\section{Evaluating the Usefulness \\ of YouTube as a Source of \\ Patient Information for \\ Neurosurgical Care in Africa: \\ A Study Protocol}

\section{CHIBUIKEM A. IKWUEGBUENYI (D) \\ LORRAINE ARABANG SEBOPELO (D) \\ MICHAEL A. BAMIMORE (D)}

GIDEON ADEGBOYEGA ID

OLORUNTOBA OGUNFOLAJI (D)

ARSENE DANIEL NYALUNDJA (D)

*Author affiliations can be found in the back matter of this article

\section{DANIEL SAFARI NTERANYA (D)}

ALICE UMUTONI (D)

PLACIDE NGOMA D

ULRICK SIDNEY KANMOUNYE (D)

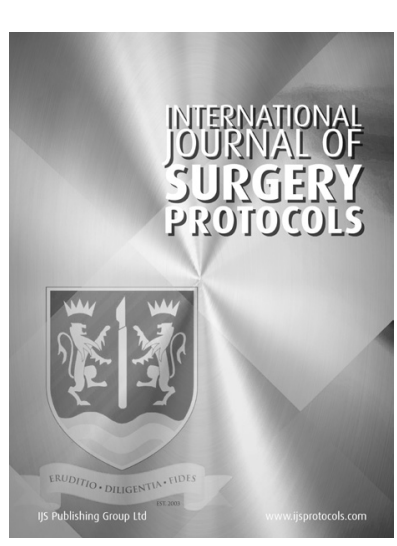

PROTOCOL

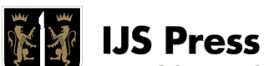

Part of the IJS Publishing Group

\title{
ABSTRACT
}

Background: A significant proportion of the public rely on the internet for their health information, and social media has emerged as the principal information source. YouTube is the world's largest and most popular video library, and it has emerged as a primary health information source because it offers animated and interactive content. However, little is known of its usefulness of neurosurgery videos to African YouTube users. We aim with this study to evaluate the usefulness of YouTube as a source of patient information for neurosurgical care in Africa.

Methodology: This observational study will be conducted using YouTube. A search will be carried out to identify neurosurgery videos suggested to African YouTube viewers from inception to September 2021. An internet browser (Google Chrome, Google Inc., CA, USA) with its cache cleared will be used to execute the search. The default YouTube search setting of "relevance" will be used to replicate what a search attempt performed by a patient would be. The first 50 results from each keyword search will be registered in a Microsoft Excel spreadsheet (Microsoft, WA, USA). The primary outcome measure is the reliability of the videos. Data will be analyzed using SPSS version 26 (IBM, WA, USA). Odds ratios and their 95\% confidence intervals will be calculated. The statistically significant level will be set at 0.05 . Also, a linear regression analysis will be performed to examine the effects of independent variables on continuous dependent variables.

Dissemination: The study findings will be published in an academic peer-reviewed journal, and the abstract will be presented at an international conference. English and French visual and video abstracts of the methods and key findings will be designed and disseminated widely on social media.

\section{Highlights:}

- A significant proportion of the public rely on the internet and social media for health information.

\section{CORRESPONDING AUTHOR:}

\section{Chibuikem A. Ikwuegbuenyi}

Immeuble Nziko, Rue Marie Gocker, Mfoundi, Yaounde, Centre, Cameroon

Ikwuegbuenyichibuikem@ gmail.com

\section{KEYWORDS:}

Africa, Health attitudes, Neurosurgery; Online video content; Social media; YouTube

TO CITE THIS ARTICLE: Ikwuegbuenyi CA, Sebopelo LA, Bamimore MA, Ogunfolaji $O$, Nyalundja AD, Adegboyega $G$, Nteranya DS, Umutoni A, Ngoma P, Kanmounye US. Evaluating the Usefulness of YouTube as a Source of Patient Information for Neurosurgical Care in Africa: A Study Protocol. International Journal of Surgery: Protocols. 2021; 25(1):pp. 244-249. DOI: https:// doi.org/10.29337/ijsp.168 
- YouTube has emerged as the world's largest video library, and has emerged as a primary health information source.

- There are few safeguards to avoid dissemination of false or biased information on the platform this could negatively influence health seeking behavior

- We aim to evaluate the usefulness of YouTube as a source of patient information for neurosurgical care in Africa.

- The findings of this study will help evaluate the volume and quantity of African neurosurgical video content and identify best practices.

\section{BACKGROUND AND RATIONALE}

A significant proportion of the public rely on the internet for their health information, and social media has emerged as the principal information source [1]. Social media platforms offer free instantaneous communication with acquaintances and their sharing features have facilitated knowledge dissemination. Social media is not without disadvantages. First, users need reliable internet access to partake in social media activities so internet access has become a determinant of health information equity. In most high-income countries (HICs) the internet is widely accessible and affordable [2]. However, internet coverage is limited and broadband costs are very high in low- and middle-income countries especially within Africa where less than $22 \%$ of Africans have reliable and affordable internet access [2]. Secondly, the instantaneous nature and wide audience of social media promote content generation. The content volume can be overwhelming for users making it difficult to identify quality and verifiable content because social network algorithm suggestions prioritize popularity over quality. The high volume of content is also a challenge for creators because they must figure out innovative ways for their content to stand out. One way most content creators do this is through animation and visualization - image or video media.

YouTube is the world's largest and most popular video library. The platform is projected to have more than 3 billion users by 2025 [3]. However, its penetration rate in Africa remains low at less than $60 \%$ primarily due to videos using up more bandwidth than other forms of content [4]. The platform has emerged as a primary health information source because it offers animated and interactive content [5]. Unfortunately, there are few safeguards or standards to avoid the dissemination of false or biased information on the platform, and the instantaneous nature of social media means that once false information is identified it is almost impossible to undo the harm that has been done. As a result, the onus of validating health-related information falls on users who are often unequipped or lack the time to vet these videos [6].

Videos published by non-medical professionals and those communicating false medical information have higher social media reach (views, likes, comments, and shares) than videos made by professionals [7]. Beyond its wide dissemination, this unverified information influences health-seeking behavior adversely. In the same vein, factual information helps improve healthseeking behavior [7] but medical professionals often lack the skills to generate engaging content [8].

Previous studies have analyzed the reliability of online patient educational videos in various aspects of neurosurgery [9-11]. However, none have evaluated videos available to African YouTube viewers. With that in mind, we aim to evaluate the usefulness of YouTube as a source of patient information for neurosurgical care in Africa. The study findings will help evaluate the volume and quantity of African neurosurgical video content and identify best practices so African neurosurgeons can improve video content.

\subsection{AIMS AND OBJECTIVES}

To evaluate the usefulness of YouTube videos on neurosurgery available to African YouTube viewers.

\section{METHODS AND ANALYSIS}

\subsection{STUDY DESIGN}

This observational study will be conducted using YouTube. A search strategy using the terms in Appendix 1 will be used to identify neurosurgery videos suggested to African YouTube viewers from inception to September 2021. The video search strategy and evaluation will be piloted among an arbitrary sample of 2 videos to identify technical issues with the strategy and evaluation.

\subsection{INCLUSION AND EXCLUSION CRITERIA}

The inclusion criteria were adapted and modified from previous studies [12, 13]. Videos made in English, French, Arabic, Swahili and Hausa will be included. This language restriction is motivated by the authors' fluency in these languages. These languages are also the most spoken in Africa. All videos unrelated to neurosurgery will be excluded.

\subsection{VIDEO SEARCH STRATEGY}

The video search strategy will be adapted and modified from previous studies evaluating healthcare-related 
YouTube content [14-16]. That is; an internet browser (Google Chrome, Google Inc, CA, USA) with its cache cleared will be used to execute the search using the keywords (Appendix 1). This search would be done on a signed in account with the browser and YouTube in incognito mode. This mode allows users to make searches that are not influenced by previous searches [17, 18]. The default YouTube search setting of "relevance" will be used to replicate what a search attempt performed by a patient would be. As most of the authors live in various African countries, the search will be done on various computers simultaneously or from a single computer with the location changed with each keyword. The first 50 results from each keyword search will be registered in a Microsoft Excel spreadsheet (Microsoft, WA, USA). The spreadsheet will be reviewed to identify duplicates and these duplicates will be deleted. Next, each video will be watched independently by two reviewers and evaluated using standardized tools (see outcome measures). The content evaluation scores will be averaged between the two independent reviewers. Conflicts with regards to video eligibility and evaluation will be discussed by the two reviewers and if they cannot agree a third reviewer (the senior author) will arbitrate.

\subsection{DATA EXTRACTION}

Basic descriptive data will be extracted from the videos, including the number of views, likes, comments, date of upload, and duration.

\subsection{OUTCOME MEASURES}

The primary outcome measure is the reliability of the videos. This will be determined using checklists: (1) modified DISCERN criteria [19], (2) the Journal of the American Medical Association (JAMA) benchmark criteria score [20]. The modified DISCERN score will be used to evaluate the clarity of videos, reliability, bias, reference supplementation, and uncertainty of content [21]. The maximum score is 5 points representing the sum of points assigned to each criterion, with higher points indicating higher reliability. The DISCERN criterion is a brief questionnaire that has been used to assess the reliability and quality of written information $[6,7]$, Table 1. The JAMA benchmark criteria score evaluates authorship, attribution, disclosure, and currency, with a maximum of 4 points [22, 23], Table 2 . Both tools have been used in the evaluation of YouTube videos [7, 23].

Secondary outcome measures include YouTube video metrics duration, video age (calculated from the upload date to the data extraction date), number of views, likes, dislikes, number of comments, number of subscribers, and references to sources. These metrics will be used to calculate the Video Power Index (VPI). The VPI assesses video popularity and is calculated as ([view ratio $\times$ like

\begin{tabular}{ll}
\hline 1 & Are the aims clear and achieved? \\
\hline 2 & Are reliable sources of information used? \\
\hline 3 & Is the information presented balanced and unbiased? \\
\hline 4 & $\begin{array}{l}\text { Are additional sources of information listed for patient } \\
\text { reference? }\end{array}$ \\
\hline 5 & Are areas of uncertainty mentioned? \\
\hline
\end{tabular}

Table 1 Modified DISCERN criteria.

Note: Adapted from Radonjic et al 2019 [7].

\begin{tabular}{lll}
\hline 1 & Authorship & $\begin{array}{l}\text { Authors and contributors, their affiliations, } \\
\text { and relevant credentials should be } \\
\text { provided }\end{array}$ \\
\hline $2 \quad$ Attribution & $\begin{array}{l}\text { References and sources for all content } \\
\text { should be listed clearly, and all relevant } \\
\text { copyright information should be noted }\end{array}$ \\
\hline 3 & Disclosure & $\begin{array}{l}\text { Website "ownership" should be } \\
\text { prominently and fully disclosed, as } \\
\text { should any sponsorship, advertising, } \\
\text { underwriting, commercial funding } \\
\text { arrangements or support, or potential } \\
\text { conflicts of interest }\end{array}$ \\
\hline 4 & Currency & $\begin{array}{l}\text { Dates when content was posted and } \\
\text { updated should be indicated }\end{array}$ \\
\hline
\end{tabular}

Table 2 Journal of the American Medical Association Score (JAMAS).

Note: Adapted from Radonjic et al 2019 [7].

ratio] $/ 100)$, where view ratio $=$ views per day, and like ratio $=($ likes $\times 100) /($ likes + dislikes $)[6,7,24,25]$.

\subsection{VIDEO CATEGORIZATION}

Videos will be classified into 4 categories based on their source: university/professional organization, medical advertising/for-profit companies, independent users, and others (i.e., news/media, governmental organization).

\subsection{DATA ANALYSIS}

Descriptive data will be used to define continuous variables (i.e., mean and standard deviation/95\% confidence interval or median and interquartile range) and categorical variables (frequency and percentage). Comparisons of 2 independent and normally distributed continuous variables will be performed with the Student t-test. Comparisons of 2 independent and non-normally distributed continuous variables were performed with the Mann Whitney $U$ test. The Spearman $r$ coefficient will be calculated to evaluate the correlation between 2 non-normally distributed continuous variables. Also, Cronbach's coefficient will be calculated to determine the consistency between 2 continuous measurements. A linear regression analysis will be performed to examine the effects 
of independent variables on continuous dependent variables. The statistically significant level will be set at 0.05 , and the statistical analysis will be performed using SPSS version 26 (IBM, WA, USA).

\section{LIMITATIONS}

We recognize several limitations in this study. First, we are limiting video analysis to YouTube excluding other equally popular video repositories like Facebook, TikTok, and WhatsApp. YouTube lends itself to a more systematic review of video content unlike the other platforms thanks to its advanced search algorithm. YouTube's search engine algorithm is inspired by the Google search algorithm. Of note, the YouTube algorithm is influenced by the geographic location of the viewer, time of posting, and level of interaction with the video [25-27]. Data will be collected on a single day, on the same computer, and, the same browser to minimize heterogeneity. Finally, only the commonest colonial languages prevalent in Africa, i.e, English and French are evaluated, videos made in other commonly spoken languages indigenous to Africa cannot be assessed for the accuracy of information passed to patients.

\section{CONCLUSION}

YouTube is an important source of health information but little is known of the usefulness of neurosurgery videos to African YouTube users. The authors will use standardized tools to independently assess the reliability of neurosurgery videos suggested to African users. In addition, they will evaluate the popularity of these videos and identify their determinants. The study findings will help improve content generation and neurosurgical patient education in Africa.

\section{ETHICAL CONSIDERATIONS}

Approval to carry out this study will not be necessary because the videos analyzed in this study will be published online.

\section{DISSEMINATION}

The study findings will be published in an academic peer-reviewed journal, and the abstract will be presented at an international conference. English and French visual and video abstracts of the methods and key findings will be designed and disseminated widely on social media.

\section{ABBREVIATIONS}

HICs, High income countries; VPI, Video power index.

\section{ADDITIONAL FILE}

The additional file for this article can be found as follows:

- Appendix 1. List of search terms. DOI: https://doi. org/10.29337/ijsp.168.s1

\section{AUTHOR CONTRIBUTIONS}

Conceptualisation: Ulrick Sidney Kanmounye.

Methodology: Chibuikem A. Ikwuegbuenyi, Arsene Daniel Nyalundja, Daniel Safari Nteranya, Alice Umutoni, Ulrick Sidney Kanmounye.

Supervision: Ulrick Sidney Kanmounye.

Writing-Original Draft: Chibuikem A. Ikwuegbuenyi, Lorraine Arabang Sebopelo, Michael A. Bamimore, Oloruntoba Ogunfolaji, Arsene Daniel Nyalundja, Gideon Adegboyega, Daniel Safari Nteranya, Alice Umutoni, Placide Ngoma, Ulrick Sidney Kanmounye.

Writing-Reviewing \& Editing:Chibuikem A. Ikwuegbuenyi, Michael A. Bamimore, Gideon Adegboyega, Ulrick Sidney Kanmounye.

\section{COMPETING INTERESTS}

The authors have no competing interests to declare.

\section{AUTHOR AFFILIATIONS}

Chibuikem A. Ikwuegbuenyi (D) orcid.org/0000-0003-3646-7713 Research Department, Association of Future African Neurosurgeons, Yaounde, Cameroon

Lorraine Arabang Sebopelo (D) orcid.org/0000-0003-3905-4834 Research Department, Association of Future African Neurosurgeons, Yaounde, Cameroon; Faculty of Medicine, University of Botswana, Gaborone, Botswana

Michael A. Bamimore (D) orcid.org/0000-0003-2235-0282 Research Department, Association of Future African Neurosurgeons, Yaounde, Cameroon; School of Medicine, Philadelphia College of Osteopathic Medicine, Philadelphia, PA, United States

Oloruntoba Ogunfolaji (D) orcid.org/0000-0002-4201-9127 Research Department, Association of Future African Neurosurgeons, Yaounde, Cameroon; College of Medicine, University of Ibadan, Ibadan, Nigeria

Arsene Daniel Nyalundja (D) orcid.org/0000-0002-4802-3928 Research Department, Association of Future African Neurosurgeons, Yaounde, Cameroon 
Gideon Adegboyega (D) orcid.org/0000-0002-8912-4338 Research Department, Association of Future African Neurosurgeons, Yaounde, Cameroon; Queen Mary University of London, Barts and The London School of Medicine London, United Kingdom

Daniel Safari Nteranya (D) orcid.org/0000-0001-5170-7442 Research Department, Association of Future African Neurosurgeons, Yaounde, Cameroon; Department of Surgery, University Clinics of Bukavu, Official University of Bukavu, Bukavu, DRC- Forensic Center, Official University of Bukavu, Bukavu, Democratic Republic of Congo

Alice Umutoni (D) orcid.org/0000-0002-8767-714X Research Department, Association of Future African Neurosurgeons, Yaounde, Cameroon; University of Rwanda, college of medicine and health sciences, kigali-Rwanda

Placide Ngoma (D) orcid.org/0000-0002-9596-9329 Research Department, Association of Future African Neurosurgeons, Yaounde, Cameroon; Medicine and Surgery, Kabwe Central Hospital, Zambia

Ulrick Sidney Kanmounye (D) orcid.org/0000-0001-6791-1018 Research Department, Association of Future African Neurosurgeons, Yaounde, Cameroon

\section{REFERENCES}

1. Gokcen HB, Gumussuyu G. A Quality Analysis of Disc Herniation Videos on YouTube. World Neurosurg. 2019; S1878-8750(19): 30246-3. DOI: https://doi.org/10.1016/j. wneu.2019.01.146

2. Bringing Africa Up to High Speed, (n.d.). https://www. ifc.org/wps/wcm/connect/NEWS_EXT_CONTENT/

IFC_External_Corporate_Site/News+and+Events/News/ CM-Stories/CM-Connecting-Africa (accessed September 1, 2021).

3. Youtube users in the World 2025, Statista. (n.d.). https:// www.statista.com/forecasts/1144088/youtube-users-inthe-world (accessed September 1, 2021).

4. YouTube penetration in selected countries and territories 2021, Statista. (n.d.). https://www.statista.com/ statistics/1219589/youtube-penetration-worldwide-bycountry/ (accessed September 1, 2021).

5. Cheng X, Dale C, Liu J. Statistics and Social Network of YouTube Videos. In: 2008 16th Interntional Workshop Qual. Serv., 2008; 229-238. DOI: https://doi.org/10.1109/ IWQOS.2008.32

6. Madathil KC, Rivera-Rodriguez AJ, Greenstein JS, Gramopadhye AK. Healthcare information on YouTube: A systematic review. Health Informatics J. 2015; 21: 173-194. DOI: https://doi.org/10.1177/1460458213512220

7. Radonjic A, Fat Hing NN, Harlock J, Naji F. YouTube as a source of patient information for abdominal aortic aneurysms. J. Vasc. Surg. 2020; 71: 637-644. DOI: https:// doi.org/10.1016/j.jvs.2019.08.230

8. Paige SR, Stellefson M, Chaney BH, Alber JM. Pinterest as a Resource for Health Information on Chronic Obstructive Pulmonary Disease (COPD): A Social Media Content Analysis. Am. J. Health Educ. 2015; 46: 241-251. DOI: https://doi.org/ 10.1080/19325037.2015.1044586
9. Samuel N, Alotaibi NM, Lozano AM. YouTube as a Source of Information on Neurosurgery. World Neurosurg. 2017; 105: 394-398. DOI: https://doi.org/10.1016/j.wneu.2017.05.111

10. Sader N, Kulkarni AV, Eagles ME, Ahmed S, Koschnitzky JE, Riva-Cambrin J. The quality of YouTube videos on endoscopic third ventriculostomy and endoscopic third ventriculostomy with choroid plexus cauterization procedures available to families of patients with pediatric hydrocephalus. J. Neurosurg. Pediatr. 2020; 1-8. DOI: https://doi.org/10.3171/2019.12.PEDS19523

11. Szmuda T, Rosvall P, Hetzger TV, Ali S, Słoniewski

P. YouTube as a Source of Patient Information for Hydrocephalus: A Content-Quality and Optimization Analysis. World Neurosurg. 2020; 138: e469-e477. DOI: https://doi.org/10.1016/j.wneu.2020.02.149

12. Rittberg R, Dissanayake T, Katz SJ. A qualitative analysis of methotrexate self-injection education videos on YouTube. Clin. Rheumatol. 2016; 35: 1329-1333. DOI: https://doi.org/10.1007/s10067-015-2910-5

13. Levin M, Wu V, Lee DJ, Cusimano MD, Lee JM. Validity and Usefulness of YouTube Videos Related to Endoscopic Transsphenoidal Surgery for Patient Information. J. Neurol. Surg. Part B Skull Base; 2021. DOI: https://doi. org/10.1055/s-0040-1722269

14. Rodriguez HA, Young MT, Jackson HT, Oelschlager BK, Wright AS. Viewer discretion advised: is YouTube a friend or foe in surgical education? Surg. Endosc. 2018; 32: 17241728. DOI: https://doi.org/10.1007/s00464-017-5853-x

15. MacLeod MG, Hoppe DJ, Simunovic N, Bhandari M, Philippon MJ, Ayeni OR. YouTube as an information source for femoroacetabular impingement: a systematic review of video content. Arthrosc. J. Arthrosc. Relat. Surg. Off. Publ. Arthrosc. Assoc. N. Am. Int. Arthrosc. Assoc. 2015; 31: 136142. DOI: https://doi.org/10.1016/j.arthro.2014.06.009

16. Erdem H, Sisik A. The Reliability of Bariatric Surgery Videos in YouTube Platform. Obes. Surg. 2018; 28: 712-716. DOI: https://doi.org/10.1007/s11695-017-2911-3

17. How Chrome Incognito keeps your browsing private - Google Chrome Help, (n.d.). https://support.google.com/chrome/ answer/9845881?hl=en\&visit_id=637703166046810146$1361658224 \& c t x=t y u \& r d=1 \mathrm{Hzippy}=\% 2 \mathrm{Ch}$ ow-incognito-mode-works (accessed October 20, 2021).

18. Browse YouTube while incognito on mobile devices YouTube Help, (n.d.). https://support.google.com/youtube/ answer/9040743?hl=en (accessed October 20, 2021).

19. Charnock D, Shepperd S, Needham G, Gann R. DISCERN: an instrument for judging the quality of written consumer health information on treatment choices. J. Epidemiol. Community Health. 1999; 53: 105-111. DOI: https://doi. org/10.1136/jech.53.2.105

20. Bullock R, Chesnut RM, Clifton G, Ghajar J, Marion DW, Narayan RK, Newell DW, Pitts LH, Rosner MJ, Wilberger JW. Guidelines for the management of severe head injury. Brain Trauma Foundation. Eur. J. Emerg. Med. Off. J. Eur. Soc. Emerg. Med. 1996; 3: 109-127. DOI: https://doi. org/10.1097/00063110-199606000-00010 
21. Singh AG, Singh S, Singh PP. YouTube for information on rheumatoid arthritis--a wakeup call? J. Rheumatol. 2012; 39: 899-903. DOI: https://doi.org/10.3899/jrheum.111114

22. Silberg WM, Lundberg GD, Musacchio RA. Assessing, controlling, and assuring the quality of medical information on the Internet: Caveant lector et viewor--Let the reader and viewer beware. JAMA. 1997; 277: 1244-1245. DOI: https://doi.org/10.1001/ jama.1997.03540390074039

23. Haymes AT, Harries V. "How to stop a nosebleed": an assessment of the quality of epistaxis treatment advice on YouTube. J. Laryngol. Otol. 2016; 130: 749-754. DOI: https:// doi.org/10.1017/S0022215116008410
24. Adhikari J, Sharma P, Arjyal L, Uprety D. Youtube as a source of information on cervical cancer. North Am. J. Med. Sci. 2016; 8: 183. DOI: https://doi.org/10.4103/19472714.179940

25. How Does the YouTube Algorithm Work in 2021? The Complete Guide. Soc. Media Mark. Manag. Dashboard; 2021. https://blog.hootsuite.com/how-the-youtube-algorithmworks/ (accessed September 12, 2021).

26. Foster D. Factors influencing the popularity of YouTube videos and users' decisions to watch them, (n.d.) 200.

27. van Es K. YouTube's Operational Logic: "The View" as Pervasive Category. Telev. New Media. 2020; 21: 223-239. DOI: https://doi.org/10.1177/1527476418818986

TO CITE THIS ARTICLE:

Ikwuegbuenyi CA, Sebopelo LA, Bamimore MA, Ogunfolaji O, Nyalundja AD, Adegboyega G, Nteranya DS, Umutoni A, Ngoma P, Kanmounye US. Evaluating the Usefulness of YouTube as a Source of Patient Information for Neurosurgical Care in Africa: A Study Protocol. International Journal of Surgery: Protocols. 2021; 25(1): pp. 244-249. DOI: https://doi.org/10.29337/ijsp.168

Submitted: 20 September 2021 Accepted: 23 October 2021 Published: 11 November 2021

\section{COPYRIGHT:}

(c) 2021 The Author(s). This is an open-access article distributed under the terms of the Creative Commons Attribution 4.0 International License (CC-BY 4.0), which permits unrestricted use, distribution, and reproduction in any medium, provided the original author and source are credited. See http://creativecommons.org/licenses/by/4.0/.

International Journal of Surgery: Protocols is a peer-reviewed open access journal published by IJS Publishing Group.

\section{IJS Press}

